\title{
Towards low-cost manufacturing of organic solar cells: multi-criteria assessment of fabrication technologies
}

\author{
N. Espinosa ${ }^{1}$, R. García-Valverde ${ }^{1}$, M. S. García-Cascales ${ }^{1}$ and A. Urbina ${ }^{1}$ \\ ${ }^{1}$ Dpto. de Electrónica, Tecnología de Computadoras y Proyectos, \\ Universidad de Politécnica de Cartagena \\ 30202 Cartagena (Spain) \\ Phone/Fax number: +0034968326514/6500, e-mail: nieves.espinosa@upct.es, rafael.gvalverde@upct.es, \\ socorro.garcia@upct.es, antonio.urbina@upct.es
}

\begin{abstract}
Solution-processed organic solar cells have recently gained considerable attention and are becoming a future solar technology option. This study is intended to improve the assessment of the operation parameters of these manufacturing technologies in order to propose a low-cost patterning technique suitable for a successful high-volume manufacturing of full organic solar cells. The assessment will take into account quantitative and qualitative parameters, such as technical issues, environmental impact or reproducibility of the fabrication output. Multi-criteria decision making methods will be used to model the problem of fabrication technique selection, combining these techniques with fuzzy numbers which serve to assess the criteria valued with linguistic labels.
\end{abstract}

\section{Key words}

Organic Solar Cells, Coating and Printing methods, Multi-criteria decision making, TOPSIS method, Fuzzy numbers.

\section{Introduction}

Steady progress has been witnessed in photovoltaic technologies since the growth of silicon crystal ingots and the development of dopant diffusion technology in the early 1950s. Breakthroughs in sputtering techniques for amorphous cells and vapour deposition had a major impact in a-Si:H and other thin film technologies such as CIS and CdTe, and finally since III-V technologies with concentration started to be deployed in terrestrial applications, we can now claim that three generations of photovoltaics are already in the market [1]. The first generation silicon wafer-based solar cells has met a second generation of lower cost thin-film technology, involving different semiconductor such as cadmium sulphide, cadmium teluride or amorphous silicon, which have been regarded as key thin-film candidates. The third generation will include high-efficiency III-V tandem cells as well as hybrid and organic technologies. Therefore, one of the most exciting areas of research over the last decade has been organic photovoltaics, a promising technology candidate for very low cost solar electricity in spite of its a priori, low efficiency. Since the development of semiconducting polymers [2], these materials have become a potential substitute of traditional semiconductors and metals in functional devices [3].

Our work is focused on full organic solar cells. In this kind of cells sunlight is absorbed by the active layer, made of a blend of polymer and fullerene derivatives as donor and acceptor materials, respectively. The polymer donor material yields an exciton that has to diffuse to the donor/acceptor interface. Since the deposition of these organic materials could be from solution, this potential advantage offers the possibility of patterning the films in high-throughput roll-to-roll techniques, which could seize on the well-known actual industry of plastic packaging techniques.

A large number of technological possibilities emerge for a massive industrial roll-to-roll production of organic solar modules. The economies of roll-to-roll methods can make plastic cells inexpensive enough to be practical in a number of uses where low price is more important than high conversion efficiency. Therefore, the field of polymeric and organic solar cells (OSC) is attracting much interest from experts, because of the easy upscaling, unrivalled in terms of production cost, processing speed, simplicity and thermal budget.

This article presents an assessment of these film-forming technologies highly suited, but little explored in the context of polymer solar cells, using a methodology based in multi-criteria decision making (MCDM), to provide support to the decision-maker in the process of identifying the ideal coating technique/s for polymer solar cells.

\section{Methodology}

Selecting a new deposition method should enable an effective balanced assessment of the following issues: 1) an increase in production capacity, 2) quality and productivity, 3) new products which are being developed, or 4) place the currently used film-forming method to know if there exists a best method to meet the 
requirements for the product. The procedure that has been used for this analysis consists of the following steps:

1. Set the product requirements and the basic data.

2. Evaluate the different capabilities of the method and set the most relevant operation parameters.

3. Choose the methodologies of MCDM that will be applied.

4. Modelling the problem.

5. Select and use the best method.

The first stage consists of establishing the window of coatability or product requirements range, and preparing a basic data document specifying these requirements.

During the second step, different coating or printing methods capabilities and operation data will be evaluated. Data are extracted from related literature [4]-[6], and coating and printing companies of new OSC markets and of the traditional packaging industry [7]-[9].

Then, parameters can be classified on two basic categories, i.e., independent and dependent ones. The former are the basic process needs, which are fixed and must be met. Dependent parameters are controlled by and arise from the independent variables, e.g. the coating speed and width are dependent variables that arise from the volume that needs to be coated in a given time.

In preparing the basic data, the best available quantitative data should be used. When uncertainty about a particular parameter was found, qualitative information from expert surveys was used.

Following, the MCDM methodologies to be applied were selected. Firstly, we perform the evaluation of the criteria using the methodology: Fuzzy Analytic Hierarchy Process (Fuzzy AHP). Once the criteria are valued, the alternatives -film forming techniques- are assessed by using TOPSIS Method, combined with Fuzzy Logic (Fuzzy TOPSIS Method) [10], [11]. The latter is considered a very useful technique to model a problem defined with vagueness or uncertain assessments.

A fuzzy model created from a set of multi-criteria deposition methods is established. This model is analyzed in order to choice the best alternative and thus to solve the decision-making problem.

Ideally, the final step will be the scale up of the selected technique for the manufacturing of OSC, in an industrial processing line.

\section{A. Problem Approach}

The first part of this paper is focused on the selection of a manufacturing process to accomplish an organic photovoltaic device.

A typical structure device comprises a multilayer structure formed from different polymers, mainly polythiophenes and fullerene blends. Each layer could be deposited by an individual film-forming technique. Nevertheless, an ideal process should involve multilayer solution processing, reducing coating and printing steps.
Regarding the used ink solution, two important aspects must be taken into account: 1) the ability of the ink to wet the surface (wettability), and 2) the capability to achieve stable films, i.e., they must not run and smear the pattern.

The process should be free from scarce and expensive materials (e.g., indium), toxic solvents and chemicals. Also the processing must ensure a low environmental impact and a high degree of recyclability of the final product.

Nowadays, a great variety of film-forming techniques that could be used in a fabrication of OLEDs (organic light-emitting diodes) and OSCs (organic solar cells) exist [12-14]. Coating and printing techniques compatible with a roll-to-roll (R2R) processing are the most promising deposition methods for organic solar cells. These R2R techniques have the potential to boost production throughputs typically by a 10 to 100 factor compared to other thin-film technologies [15].

The evaluated techniques in this study have been identified amongst the different known so far, and will be considered as the alternatives -from A1 to A10 showed in Table I-, for the decision-making problem. Note that only those techniques having R2R compatibility have been selected.

Table I. Set of deposition methods considered as alternatives

\begin{tabular}{ll} 
Coating methods & Printing methods \\
\hline A1. Doctor blade & A6. Screen \\
A2. Knife over edge & A7. Inkjet
\end{tabular}

$\begin{array}{ll}\text { A3. Slot die } & \text { A8. Gravure } \\ \text { A4. Slide } & \text { A9. Flexography } \\ \text { A5. Curtain } & \text { A10. Offset }\end{array}$

Once the process requirements and the technological alternatives are defined, the selection of the dependent criteria was made. The parameters which have served to evaluate the alternatives, both quantitatively and qualitatively, have been established in a hierarchy and grouped as follows:

1) Design control (C1). It is considered as the capability to obtain a stable morphology of the deposited layers and the required patterning. In this sense, the most advantageous methods deposit layers with uniformity and precision in $\mathrm{z}$ axis, and allow for a multiple-layer structure in an OSC.

- Thickness control (C11). Final thickness depends on the following criteria:

- Wet thickness (C111). Is defined as the thickness of the deposited layer before solvent evaporation. Here it is fixed by the method in the range of $\mu \mathrm{m}$. Typical desired thickness for OSC is in the nanoscale.

- Volatility (C112). It controls the drying step, where chemical and physical properties of the product can be affected. It 
was expressed as a linguistic label for each one of these 10 alternatives.

- $\quad$ Speed (C113). Line speed can control the final coating weight in many methods, mainly pre-metered coating.

- Dimensional control (C12): control of the deposition is important for setting the pattern characteristics, stripes, shapes, layer thickness, etc.

- Number of layers (C13): the capability to coat simultaneously several layers can result in an unexpected improvement of the manufacturing efficiency.

2) Ink properties (C2). Rheological properties of polymer or solutions influence in terms of operation for each of these techniques. This criterion here is only related to the coating technique, not to the interaction ink-surface (such as wettability or surface tension)

- Viscosity (C21). It determines the final weight in doctored coating methods and the thickness in printing ones. However, in pre-metered methods it does not affect to the final thickness layers.

- Ink Preparation (C22). Here is label valued. Depending on the method, the final coating solution contains solvents, binders, pigments, colorants, cross-linkers, surfactants to achieve the desired solution characteristics.

3) Reproducibility (C3). One of the major challenges in OSC processing is to reach reproducible, in terms of morphology, electronic transport properties and power conversion efficiency, which has not until date been achieved.
4) Energy input (C4). Reducing the energy consumption during manufacturing is one of the expected improvements of OSC. Here is defined qualitatively by comparison through linguistic labels.

- Ink Waste (C41). The solution waste could influence in the input of materials and thus in the input of energy.

- Maximum throughput (C42). The amount of solar cells area produced in a period of time, here expressed in $\mathrm{m}^{2} / \mathrm{h}$.

- Embedded Energy (C43). It is the embodied energy used for the direct processing per functional unit, which was estimated with linguistic labels, not having quantitative values. The energy embedded in the materials is not entered in this parameter, because is already considered in Ink waste.

It will lead to a hierarchic structure with two levels as the representation of this problem as shown in Fig. 1 and the evaluation of the criteria related to each method can be seen in Table II. This table constitutes the decision matrix.

\section{B. Multi-criteria methodologies. Problem Modelling.}

Practical problems are often characterized by several non commensurable and conflicting criteria, and there may be no solution satisfying all criteria simultaneously. Thus, the solution is a compromise solution according to the decision- maker preferences, and therefore should include trade-offs between different proposed solutions. The information is located in a set of labels, and in a later step the decision-maker expresses his/her intuition about the meaning of these linguistic terms by means of fuzzy numbers.

Table II. Matrix of decision making

\begin{tabular}{|c|c|c|c|c|c|c|c|c|c|c|c|}
\hline & \multicolumn{5}{|c|}{ DESIGN CONTROL } & \multicolumn{2}{|c|}{ INK PROPERTIES } & \multirow{3}{*}{ REPRODUCIBILITY } & \multicolumn{3}{|c|}{ ENERGY INPUT } \\
\hline & \multicolumn{3}{|c|}{ Thickness Control } & \multirow[b]{2}{*}{$\begin{array}{c}\text { Dimensional } \\
\text { Control }\end{array}$} & \multirow[b]{2}{*}{$\begin{array}{l}\text { Number } \\
\text { of layers }\end{array}$} & \multirow[b]{2}{*}{$\begin{array}{c}\text { Viscosity } \\
(\mathbf{P a} \cdot \mathbf{s})\end{array}$} & \multirow[b]{2}{*}{$\begin{array}{c}\text { Ink } \\
\text { preparation }\end{array}$} & & \multirow[b]{2}{*}{$\begin{array}{c}\text { Ink } \\
\text { waste }\end{array}$} & \multirow[b]{2}{*}{$\begin{array}{c}\text { Max. } \\
\text { Throughput } \\
\left(\mathrm{m}^{2} / \mathrm{h}\right)\end{array}$} & \multirow[b]{2}{*}{$\begin{array}{c}\text { Embedded } \\
\text { energy }\end{array}$} \\
\hline & $\begin{array}{c}\text { Wet } \\
\text { thickness } \\
(\mu \mathrm{m})\end{array}$ & Volatility & $\begin{array}{c}\text { Speed } \\
(\mathrm{m} / \mathrm{min})\end{array}$ & & & & & & & & \\
\hline $\begin{array}{l}\text { A1. DOCTOR } \\
\text { BLADE }\end{array}$ & $10-100$ & medium & $0.001-0.1$ & 0 & 1 & $0.01-40$ & simple & very low & low & low & high \\
\hline $\begin{array}{l}\text { A2. KNIFE OVER } \\
\text { EDGE }\end{array}$ & $10-750$ & low & $1-100$ & 0 & 1 & $0.05-100$ & moderate & very low & very low & 5000 & medium \\
\hline A3. SLOT DIE & $10-500$ & medium & $1-1000$ & 1 & 3 & $0.01-300$ & moderate & high & very low & 50000 & low \\
\hline A4. SLIDE & $25-250$ & medium & $1-1000$ & \begin{tabular}{|c|} 
pseudo/quasi \\
$2 / 3$
\end{tabular} & 17 & $0.01-300$ & critical & high & very low & 100000 & low \\
\hline A5. CURTAIN & $5-500$ & high & $10-1000$ & $\begin{array}{c}\text { pseudo/quasi } \\
2 / 3\end{array}$ & 17 & $0.015-2$ & critical & high & very low & 100000 & low \\
\hline A6. SCREEN & $3-500$ & low & $0.01-100$ & 2 & 1 & $0.1-100$ & demanding & low & very low & 100 & high \\
\hline A7. INKJET & $0.3-500$ & high & $0-1$ & digital master & 1 & $\begin{array}{c}0.001- \\
0.01\end{array}$ & moderate & medium & very low & 50 & high \\
\hline A8. FLEXOGRAPHY & $0.8-200$ & very high & $1-1000$ & 2 & 1 & $0.01-1$ & demanding & high & very low & 50000 & very low \\
\hline A9. GRAVURE & $0.8-80$ & very high & $1-1000$ & 2 & 1 & $0.01-2.5$ & difficult & high & very low & 100000 & very low \\
\hline A10.OFFSET & $3-210$ & very low & $3-300$ & 2 & 1 & $2-100$ & $\begin{array}{c}\text { demanding- } \\
\text { difficult }\end{array}$ & medium & very low & 50000 & medium \\
\hline
\end{tabular}




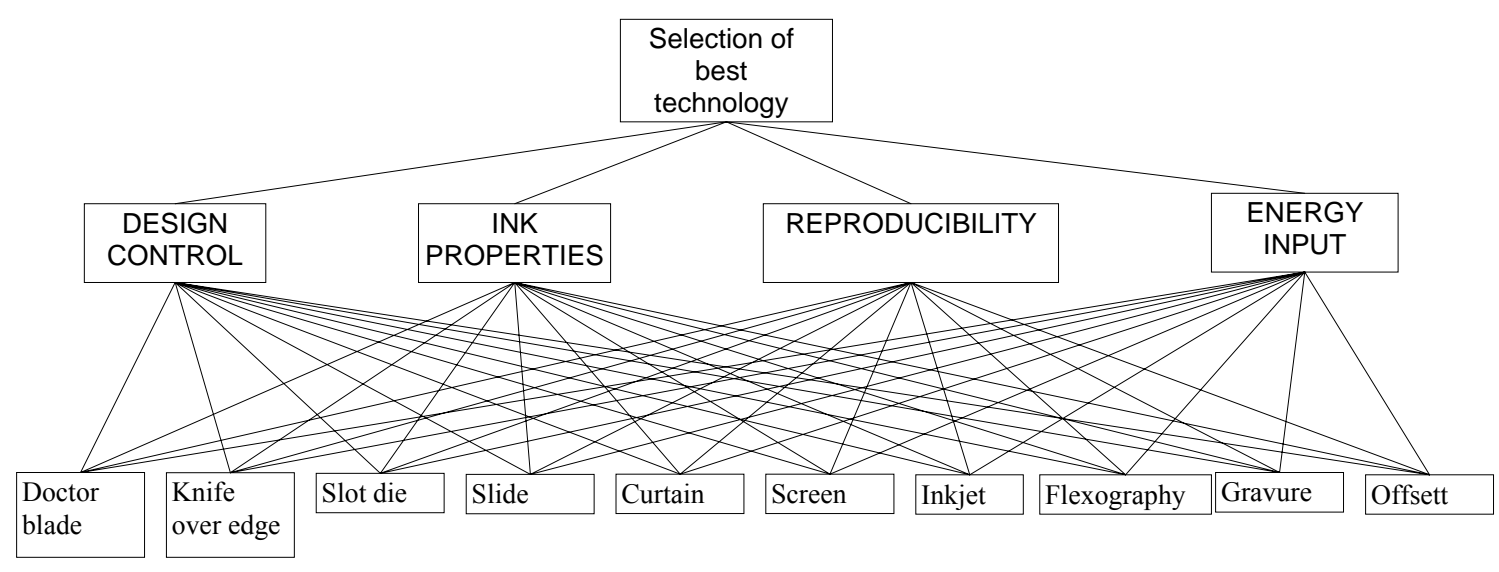

Fig. 1. Hierarchy structure of the film-forming method decision problem

The MCDM techniques help the decision- maker to articulate his/her preferences in a complex decision making environment. As is well known, the analytic hierarchy process (AHP) [16] is a simple MCDM to deal with unstructured and multi criteria problems, which was developed by Saaty (1980). It consists of decomposing a complex problem into its components, organizing the components into levels to generate a hierarchical structure. The aim of constructing this hierarchy is to determine the impact of the lower level on an upper level, which is achieved by paired comparisons provided by the decision-maker. In this case, the Fuzzy AHP was only used in order to obtain the weight of each criteria in the decision problem.

In AHP problems, where the values are fuzzy, not crisp; instead of using lambda as an estimator to the weight, we will use the geometric normalized average, in Eq. 1:

$$
\omega_{i}=\frac{\left(\prod_{j=1}^{n}\left(a_{i j}, b_{i j}, c_{i j}\right)\right)^{1 / n}}{\sum_{i=1}^{m}\left(\prod_{j=1}^{n}\left(a_{i j}, b_{i j}, c_{i j}\right)\right)^{1 / n}}
$$

Table III. Importance weight of criteria

\begin{tabular}{cccc}
\hline & \multicolumn{3}{c}{ Normalized } \\
\hline C1 & 0.3636 & 0.3947 & 0.4138 \\
C11 & 0.2815 & 0.3148 & 0.3348 \\
C111 & 0.1987 & 0.2344 & 0.2592 \\
C112 & 0.0248 & 0.0335 & 0.0432 \\
C113 & 0.0331 & 0.0469 & 0.0648 \\
C12 & 0.0313 & 0.0350 & 0.0418 \\
C13 & 0.0352 & 0.0450 & 0.0558 \\
\hline C2 & 0.0606 & 0.0789 & 0.1034 \\
C21 & 0.0303 & 0.0395 & 0.0517 \\
C22 & 0.0303 & 0.0395 & 0.0517 \\
\hline C3 & 0.3636 & 0.3947 & 0.4138 \\
\hline C4 & 0.0909 & 0.1316 & 0.2069 \\
C41 & 0.0022 & 0.0060 & 0.0110 \\
C42 & 0.0352 & 0.0837 & 0.2648 \\
C43 & 0.0176 & 0.0419 & 0.0662 \\
\hline
\end{tabular}

As a result of the AHP method application in the problem of a deposition method selection,

Table III with the weights of the criteria is obtained.

The Technique for Order Performance by Similarity to Ideal Solution (TOPSIS) is one of the well known classical MCDM methods, developed in 1981 by Hwang and Yoon [11]. In this study, the TOPSIS method, which is very simple and easy to implement (Fig. 2), was used to select the preference order of the alternatives. The MCDM that includes both numeric and linguistic labels can be expressed in a matrix.

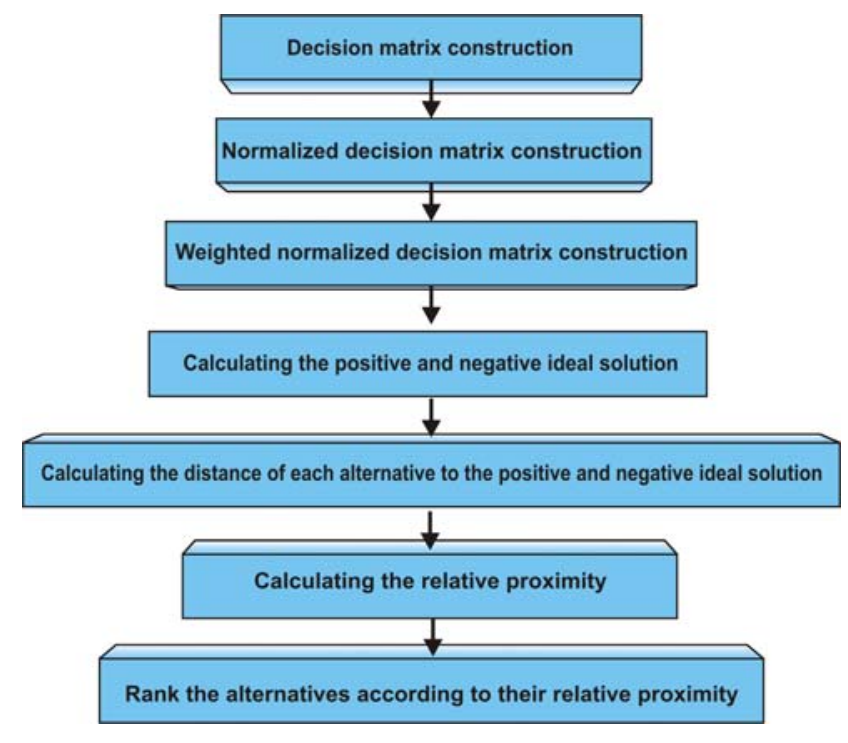

Fig. 2. TOPSIS algorithm steps

The fuzzy TOPSIS methods are derived from the generic TOPSIS method with minor differences, with the pertinent adaptation of the operations associated to the linguistic labels [10].

The chosen alternative should have the shortest distance from the positive ideal solution (PIS) and the farthest from the negative ideal solution (NIS). The final ranking is obtained by means of the closeness index. 


\section{Results}

In Table IV, the fuzzy numbers of the ranking score are presented.

Table IV. The ranking score, computing the distance to ideal solution $\mathrm{d}+$ and the negative ideal solution $\mathrm{d}$-, by fuzzy numbers.

\begin{tabular}{|c|c|c|c|c|}
\hline \multirow{10}{*}{$\mathrm{d}+$} & $\mathrm{A}_{1}$ & 0.0512 & 0.0772 & 1239 \\
\hline & $\mathrm{A}_{2}$ & 0.0508 & 0.0744 & 228 \\
\hline & $\mathrm{A}_{3}$ & 0466 & & \\
\hline & $\mathrm{A}_{4}$ & 0.0790 & 1211 & 0.1548 \\
\hline & $\mathrm{A}_{5}$ & 0.0210 & 0.0347 & 0.0660 \\
\hline & $\mathrm{A}_{6}$ & 0.0290 & 0.0436 & 0.0899 \\
\hline & $\mathrm{A}_{7}$ & & & 0.0753 \\
\hline & $A_{8}$ & 0.0264 & 0.0347 & 0.0672 \\
\hline & $\mathrm{A}_{9}$ & 0250 & 0.0340 & 0.0672 \\
\hline & $\mathrm{A}_{10}$ & & 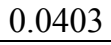 & .0683 \\
\hline \multirow{10}{*}{ d- } & & 54 & 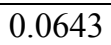 & .0740 \\
\hline & $\mathrm{A}_{2}$ & 0401 & & 0.0631 \\
\hline & $\mathrm{A}_{3}$ & 3 & & 0.0815 \\
\hline & $\mathrm{A}_{4}$ & & & 0.0770 \\
\hline & $\mathrm{A}_{5}$ & 0.0670 & 0.1023 & 0.1244 \\
\hline & $\mathrm{A}_{6}$ & 0.0794 & 0.1 & 0.1464 \\
\hline & $\mathrm{A}_{7}$ & & & 0.1557 \\
\hline & $\mathrm{A}_{8}$ & & 0.1 & 0.1594 \\
\hline & $\mathrm{A}_{9}$ & 2 & 8 & 0.1594 \\
\hline & $\mathrm{A}_{10}$ & & & 0.1572 \\
\hline & $\mathrm{A}_{1}$ & & & 0.8072 \\
\hline & $\mathrm{A}_{2}$ & & & 0.6937 \\
\hline & $\mathrm{A}_{3}$ & 31 & 0.4 & 0.9174 \\
\hline & $\mathrm{A}_{4}$ & 1355 & 0.2829 & 0.6971 \\
\hline & $\mathrm{A}_{5}$ & & & 1.4150 \\
\hline & $\Delta$ & & & 1.3509 \\
\hline & $\mathrm{A}_{7}$ & & & 1.4414 \\
\hline & $\mathrm{A}_{8}$ & 42 & 0.7820 & 1.4940 \\
\hline & $\mathrm{A}_{9}$ & & 0.7873 & 1.5002 \\
\hline & & 0.3533 & 0.7527 & 1.4584 \\
\hline
\end{tabular}

Considering Fig. 3, where the score corresponding to each technology in fuzzy numbers is represented, a defuzzyfication process is needed in order to obtain the order of preference of the alternatives [17].

From these results, we can conclude that three groups seem to appear in which the technologies have similar score:

- First score group, formed by Gravure, Flexography, Offset, Inkjet, Curtain and Screen. All of them have a short distance to positive ideal solution, because their operation values are inside the window of coatability, and they could fulfil the coating requirements of an organic solar cell. Furthermore, this first group reveals a certain predominance of printing techniques over coating ones.

- Second score group, formed by Slot die, Doctor Blade, Knife over edge. The cited technologies have a farther distance to ideal solution, but could be acceptable methods.
- Third group is Slide coating scored as the worst technique for the purpose of organic layers deposition, mainly due to the low score in criteria such as Thickness control, Reproducibility and Maximum throughput, which are parameters with high weights in the criteria selection process.

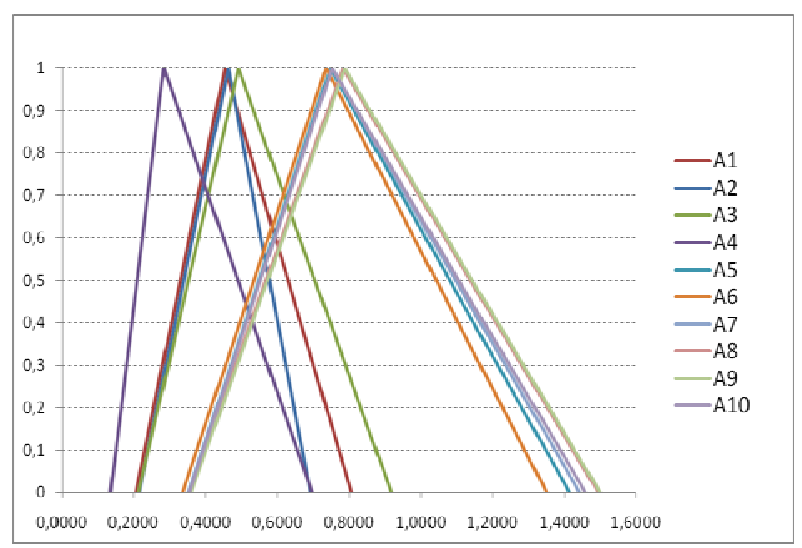

Fig. 3. Ranking score graphically.

\section{Conclusions}

This paper discusses several aspects of the most suitable coating and printing processes to accomplish the fabrication of an organic photovoltaic device, and aims to provide a broad understanding of the many different techniques that could be used in polymer solar cells.

There are approximately 1000 different coating configurations that are available and are in use. The operating range of any method depends on solution viscosity and wet thickness, line speed, desired quality level, thickness uniformity, cost, the fluid flow mechanisms in the method and the manufactured precision of the applicator.

As a result no one method is capable of applying a quality coating over the wide range of potential coating conditions and each method has an optimum range in which it should be operated. Outside of this optimum range quality and reproducibility will deteriorate.

In order to obtain a commercially successful coating process this assessment was carried out. Different methods may be needed as product moves form laboratory to full production. Therefore, selecting the correct method is a key part of the scale-up process for organic solar cells manufacturing.

The applied MCDM methodologies show the stratification in three groups of techniques; one includes the winner methods, having similar score (Gravure, Flexography, Offset, Inkjet, Curtain, Screen), followed by the second techniques group not so far from the first (Slot die, Doctor Blade, Knife over edge) and the third group, only formed by Slide coating, which is the worst scored technique. 
The results have revealed a relative predominance of printing techniques over coating ones, which was expected in a way.

Future work will be aimed to establish most closely the operation window of each one of the techniques; also a weighted balance of the importance of the different parameters using in the assessment of the techniques could be improved if more experts could contribute to the survey.

\section{Acknowledgement}

We acknowledge the financial support from the following programs of the Spanish government: Consolider HOPE, CSD2007-00007, of the Comunidad Autónoma de la Región de Murcia, CARM D429-2008 and of the DGICYT under project TIN2008-06872-C0404 .

\section{References}

[1] M. A. Green. Third Generation Photovoltaics: Advanced Solar Energy Conversion. Springer Series in Photonics (2003). pp. 1-4.

[2] G. Yu, J. Gao, J. C. Hummelen, F. Wudl, and A. J. Heeger. "Polymer photovoltaic cells: Enhanced efficiencies via a network of internal donor-acceptor heterojunctions" in Science, Vol. 270(5243) pp. 1789-1791, 1995.

[3] C. J. Brabec, N. S. Sariciftci, and J.C. Hummelen, "Plastic solar cells" in Advanced Functional Materials, Vol. 11, pp. 1526, 2001.

[4] E.D. Cohen and E.B. Gutoff, Kirk-Othmer Enclyclopedia of chemical technology, chapter "Coating Processes". JohnWiley \& Sons, Hoboken, (2007).

[5] E.B. Gutoff and E.D. Cohen, Coating and drying defects: Toubleshooting operating problems, Wiley-Interscience, Hoboken, (2006).

[6] E. B. Gutoff and E. D. Cohen, Multilayer flexible Packaging, chapter Water and solvent-based coating technology, Material Science and Process Technology. Elsevier, (2010), pp. 163-184.

[7] Konarka Technologies Inc. [Last check: Jan 2010].

[8] PixDro Ltd. Industrial Inkjet Solutions. Printing OLED Plastic electronic [Last check: Jan 2010].

[9] Extrusion Dies Industries. LLC [Last check: Jan 2010].

[10] M. S. Garcia-Cascales and M. Teresa Lamata. "Multicriteria analysis for a maintenance management problem in an engine factory: rational choice" in Journal of Intelligent Manufacturing, 2009.

[11] Hwang, C.L., Yoon, K.,. Multiple Attribute Decision Methods and Applications. Springer, Berlin. (1981)

[12] F. C. Krebs. "Fabrication and processing of polymer solar cells: A review of printing and coating techniques", in Solar Energy Materials and Solar Cells, Vol. 93, pp. 394-412, 2009.

[13] A. C. Hübler and H. Kempa, Roll-to-Roll Processing of Thin- Film Organic Seminconductors, chapter 19. Weinheim: Wiley-Vch, (2008)

[14] B. J. deGans, P. C Duineveld and U. S Schubert, "Inkjet printing of polymers: State of the art and future developments", in Advanced Materials, Vol.16(3), pp. 203-213, 2004.

[15] G. Dennler, C. J. Brabec. Eds: C. J. Brabec, U. Scherf, V. Dyakonov Organic Photovoltaics: Materials, Device Physics, and Manufacturing Technologies. Wiley-VCH, Weinheim (2008).

[16] T.L. Saaty, The Analytic Hierarchy Process: Planning, Priority Setting, Resource Allocation, McGraw-Hill, (1980).

[17] M.S., Garcia-Cascales and M.T. Lamata, "A modification to the index of Liou and Wang for ranking fuzzy number", in International Journal of Uncertainty, Fuzziness and KnowledgeBased Systems, pp. 411-424, 2007. 